\title{
Erratum to: Two Streptomyces Species Producing Antibiotic, Antitumor, and Anti-Inflammatory Compounds Are Widespread Among Intertidal Macroalgae and Deep-Sea Coral Reef Invertebrates from the Central Cantabrian Sea
}

\author{
Alfredo F. Braña • Hans-Peter Fiedler • Herminio Nava • Verónica González • \\ Aida Sarmiento-Vizcaíno • Axayacatl Molina • José L. Acuña • Luis A. García • \\ Gloria Blanco
}

Published online: 13 November 2014

(C) Springer Science+Business Media New York 2014

Erratum to: Microb Ecol (2014)

DOI 10.1007/s00248-014-0508-0

The original version of this article unfortunately contains mistakes in the name of the first author and also in the initials name in the headings on the top of the rest of the pages. The correct name of the first author is ALFREDO F. BRAÑA as corrected above. In the initials of the page headings, it should say A.F. Braña et al.

The online version of the original article can be found at http://dx.doi.org/ 10.1007/s00248-014-0508-0.

A. F. Braña · V. González · A. Sarmiento-Vizcaíno · G. Blanco $(\bowtie)$

Departamento de Biología Funcional, Área de Microbiología, e Instituto Universitario de Oncología del Principado de Asturias,

Universidad de Oviedo, 33006 Oviedo, Spain

e-mail: gbb@uniovi.es

H.-P. Fiedler

Mikrobiologisches Institut, Universität Tübingen, 72076 Tübingen,

Germany

H. Nava

Departamento de Biología de Organismos y Sistemas. Área de

Botánica, Universidad de Oviedo, Oviedo, Spain

A. Molina $\cdot$ J. L. Acuña

Departamento de Biología de Organismos y Sistemas. Área de

Ecología, Universidad de Oviedo, Oviedo, Spain

L. A. García

Departamento de Ingeniería Química y Tecnología del Medio

Ambiente. Área de Ingeniería Química, Universidad de Oviedo,

Oviedo, Spain 